\title{
Increased galectin-3 expression and intra-epithelial neutrophils in small airways in severe COPD
}

\author{
C. Pilette*, B. Colinet*, R. Kiss”, S. Andréđ, H. Kaltner", H-J. Gabius ${ }^{\Uparrow}$, M. Delos ${ }^{+}$, \\ J-P. Vaerman*, M. Decramer ${ }^{\S}$ and Y. Sibille*
}

ABSTRACT: Galectins-1 and $\mathbf{- 3}$ regulate epithelial proliferation/apoptosis and neutrophil activation, and are implicated in lung cancer and asthma. The role of galectins in chronic obstructive pulmonary disease (COPD), characterised by epithelial changes and neutrophil infiltration, remains unknown.

In the present study, galectin-1 and -3 expression was assessed by immunohistology in the bronchial epithelium of lung specimens from eight severe COPD patients and compared with nine nonsmokers and six smokers without COPD. Findings were related to epithelial proliferation (Ki67), tissue inflammation and lung function.

Epithelial galectin-3 immunostaining was increased only in the small airways of COPD patients when compared with nonsmokers and smokers. In contrast, galectin-1 was only significantly increased in the small airways of the group of smokers. Ki-67+ epithelial cells and neutrophils were increased in the small airways of COPD patients when compared with smokers. Furthermore, intra-epithelial neutrophils correlated in the small airways with Ki-67+ epithelial cells and with the forced expiratory volume in one second/forced vital capacity ratio. However, no correlation was observed with galectin expression.

The present study supports the hypothesis that distal airways represent an important site for detecting changes in chronic obstructive pulmonary disease. In patients with severe disease, an increased galectin-3 expression and neutrophil accumulation in the small airway epithelium was demonstrated, correlating with epithelial proliferation and airway obstruction.

KEYWORDS: Epithelial proliferation, galectin, hyperplasia, inflammation, lung

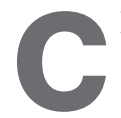
hronic obstructive pulmonary disease (COPD) is a frequent disorder characterised mostly by irreversible airway obstruction that develops in susceptible smokers [1]. During the course of the disease, COPD airways are infiltrated by neutrophils, macrophages and T-cells (especially CD8+) through the upregulation of adhesion molecules, such as intercellular adhesion molecule-1 or CXC chemokine receptor $3[2,3]$. However, the pathways involved in the persistence of recruited leukocytes, especially neutrophils, in the bronchi of COPD patients remain to be identified. Furthermore, there are differences in the leukocyte phenotypes present in COPD airways with regard to disease severity and microlocalisation within bronchial tissues [4].

In addition to inflammatory changes, COPD airways also undergo structural remodelling [5]. This includes: 1) increased number and size of mucous acini in submucosal glands; 2) hyperplasia and metaplasia of surface mucus-secreting goblet cells in large and small airways, respectively; and 3) squamous metaplasia [5]. The mechanisms leading to the aforementioned changes are unknown. Additionally, the bronchial epithelium function is affected in COPD patients, with upregulated expression of cytokines/chemokines [6], such as interleukin (IL)-8 or macrophage inflammatory protein- $1 \alpha$ and $-1 \beta$, and downregulation of proteins, such as the polymeric immunoglobulin (Ig) receptor [7], probably following degradation by neutrophil enzymes [8].

Galectins are galactose-binding proteins that are involved in lung physiology [9-12]. Galectin-3 can enhance the proliferation of respiratory epithelial cells by limiting adhesion to the basement membrane through competition with integrin receptors for the binding of laminin in the extracellular matrix [13]. Galectins-1 and -3 are also involved in apoptosis regulation via binding

\section{AFFILIATIONS}

*Unit of Pneumology and Microbiology, University of Louvain (UCL), and

\#Laboratory of Toxicology, Pharmacy School, University of Brussels, Brussels,

+Laboratory of Histopathology, UCL Mont-Godinne, Yvoir, and

${ }^{\S}$ Laboratory of Pneumology, University of Leuven, Leuven, Belgium.

"Institute of Physiological Chemistry, Ludwig-Maximilians University, Munich, Germany.

\section{CORRESPONDENCE}

C. Pilette

Unit of Pneumology and

Microbiology

University of Louvain

Avenue Hippocrate 54/5490

Brussels B-1200

Belgium

Fax: 327649440

E-mail: charles.pilette@

pneu.ucl.ac.be

Received:

June 252005

Accepted after revision:

January 032007

\section{SUPPORT STATEMENT}

C. Pilette was a research assistant of the Foundation de la Recherche Scientifique (FRSM; Brussels, Belgium). The present study was partly supported by grant №. 3.4590.99 from the FRSM and a grant from the Mizutani Foundation for Glycoscience (Tokyo, Japan).

\section{STATEMENT OF INTEREST}

None declared.

European Respiratory Journal

Print ISSN 0903-1936

Online ISSN 1399-3003 
to the cell surface or cytoplasmic ligands, such as glycans of the fibronectin receptor, CD7 or intracellular proteins, such as Bcell leukaemia/lymphoma 2 gene product $[10,14]$. The nuclear and/or cytoplasmic pattern of galectin-3 expression could play a role during malignant transformation, as suggested in breast cancer [15]. In addition, galectin-3 is known to: 1) trigger the release of oxygen metabolites and elastase by neutrophils and macrophages; 2) enhance macrophage phagocytosis; and 3) stimulate natural killer cell activity and IL-1 production $[14,16]$. It also represents an adhesion molecule independent from selectins and $\beta_{2}$-integrins that underlie neutrophil recruitment to the lung during streptococcal pneumonia $[17,18]$. In contrast, galectin-1 inhibits tumour necrosis factor- $\alpha$ production by monocytes/macrophages [14], suggesting that galectin-1 and -3 have balanced, opposite effects on cell apoptosis/proliferation and phagocyte activation. It is noteworthy that these two lectins are abundantly expressed in the lung $[11,18]$.

The role of galectin- 3 has been evaluated in lung cancer and asthma, whereas its role in COPD remains unknown. Therefore, the expression of galectins- 1 and -3 in the bronchial epithelium of both large and small airways was evaluated by immunohistochemistry from eight patients with severe COPD undergoing lung transplantation. Lung specimens from nine nonsmokers and six smokers without COPD were used as controls. Findings on galectin expression were related to clinical parameters of airflow limitation, epithelial proliferation (Ki-67 expression) and tissue accumulation of neutrophils, macrophages and T-cells in the epithelium and lamina propria, in both large and small airways.

\section{MATERIALS AND METHODS}

\section{Patients}

COPD patients were recruited from a population undergoing lung transplantation, as previously described elsewhere [7]. Eight very severe COPD patients classified as stage IV, according to the Global Initiative for Chronic Obstructive Lung Disease classification [1], were included. The mean (range) age was $52(42-60)$ yrs. The COPD patients were exsmokers, had symptoms of chronic bronchitis and all but one were treated by inhaled corticosteroids. Controls consisted of six patients, aged 60 (42-74) yrs, recruited from a population of smokers without COPD and nine nonsmokers (mean age 62 yrs) undergoing lung surgery for a solitary peripheral lung tumour. All patients were clinically stable with no evidence of lung infection at the time of surgery. Pulmonary function tests were performed $37 \pm 26$ (mean $\pm \mathrm{SD}$ ) days before surgery. For each patient, random tissue blocks (three to 11 per patient) were sampled in central and peripheral areas from each lobe of one or both lungs (single or bipulmonary transplantation), fixed under constant inflation pressure $\left(30 \mathrm{cmH}_{2} \mathrm{O}\right)$ in $4 \%$ formaldehyde and processed for immunohistochemistry. Patient characteristics are presented in table 1.

\section{Immunohistochemistry}

Tissue sections were processed for galectin immunostaining. Endogenous peroxidase activity was inhibited by incubation in $0.03 \% v / v \mathrm{H}_{2} \mathrm{O}_{2}$ and sections were blocked by normal horse serum and avidin/biotin blocking kit (Dako, Glostrup, Denmark). Sections were then treated for 30 min with 1:100

\begin{tabular}{|c|c|c|c|}
\hline & Nonsmokers & Smokers & COPD \\
\hline Subjects $n$ & 9 & 6 & 8 \\
\hline Age yrs & $62 \pm 14$ & $60 \pm 7$ & $53 \pm 2$ \\
\hline Male/female & $4 / 5$ & $4 / 2$ & $5 / 3$ \\
\hline Smoking history pack-yrs & 0 & $39 \pm 15^{*}$ & $35 \pm 4^{*}$ \\
\hline FEV $1 \%$ pred & $104 \pm 10$ & $103 \pm 3$ & $23 \pm 2^{*}$ \\
\hline FEV $1 /$ FVC $\%$ & $77 \pm 6$ & $73 \pm 5$ & $39 \pm 4^{\star}$ \\
\hline TLC \% pred & $113 \pm 5$ & $100 \pm 4$ & $122 \pm 7^{*}$ \\
\hline FRC $\%$ pred & $113 \pm 16$ & $96 \pm 1$ & $196 \pm 11^{*}$ \\
\hline RV \% pred & $136 \pm 31$ & $94 \pm 2$ & $236 \pm 25^{*}$ \\
\hline DL,Co \% pred & $86 \pm 10$ & $80 \pm 7$ & $24 \pm 3^{*}$ \\
\hline $\mathrm{Pa}, \mathrm{O}_{2} \mathrm{mmHg}$ & NA & NA & $61 \pm 3$ \\
\hline $\mathrm{Pa}, \mathrm{CO}_{2} \mathrm{mmHg}$ & NA & NA & $44 \pm 2$ \\
\hline
\end{tabular}

Data are presented as mean $\pm \mathrm{SD}$, unless otherwise stated. COPD: chronic obstructive pulmonary disease; FEV1: forced expiratory volume in one second; $\%$ pred: \% predicted; FVC: forced vital capacity; TLC: total lung capacity; FRC: functional residual capacity; RV: residual volume; $D \mathrm{~L}, \mathrm{CO}$ : diffusing capacity of the lung for carbon monoxide; $\mathrm{Pa}_{\mathrm{a}_{2}}$ : arterial oxygen tension; $\mathrm{Pa}_{\mathrm{a}} \mathrm{CO}_{2}$ : carbon dioxide arterial tension; NA: not available. Lung function tests, including $D \mathrm{~L}, \mathrm{CO}$, and blood gases were evaluated before lung surgery; only blood gas values under oxygen supplementation were available in the months preceding lung transplantation. *: $p<0.05$ compared with nonsmokers (Mann-Whitney U-test)

rabbit polyclonal anti-human galectin-1 or -3 antibodies, which had been rigorously tested for specificity by ELISA and Western blotting $[12,19,20]$. Control sections were incubated with normal rabbit serum (1:100). Biotinylated horse antirabbit IgG (1:100) was used as secondary antibody and sections were incubated with avidin-biotin-horseradish peroxidase (ABC standard kit of Vectorstain; Dako). After revelation with 3,3'-diaminobenzidine tetrahydrochloride and $0.03 \% \mathrm{H}_{2} \mathrm{O}_{2}$, sections were counterstained with Toluidine blue.

Leukocytes were detected using specific antibodies to neutrophil elastase (neutrophils), CD68 (monocytes/macrophages) and CD3 (T-lymphocytes). For macrophages and T-cells, antigen retrieval was performed using microwave treatment (five cycles of $3 \mathrm{~min}, 350$ Watts) in $0.01 \mathrm{M}$ citrate buffer, $\mathrm{pH}$ 5.7. Endogenous peroxidase activity was inhibited by incubation in $0.03 \% \mathrm{H}_{2} \mathrm{O}_{2}$ and sections were blocked with $1 \%$ bovine serum albumin. Sections were then incubated with mouse monoclonal antibodies to neutrophil elastase (mIgG1 $\kappa$, clone NP57; Dako) or CD68 (mIgG3к, clone PG-M1; Dako) or with polyclonal rabbit antibody to CD3 (Dako). Control sections were treated as appropriate with normal rabbit serum or mouse IgG isotype. Secondary antibodies were biotinylated goat anti-rabbit IgG or goat anti-mouse IgG (Dako). The reaction was amplified by incubation with streptavidinperoxidase conjugate and revealed using diaminobenzidine and $\mathrm{H}_{2} \mathrm{O}_{2}$. Sections were counterstained with Mayer's hemalum and mounted with coverslips in Eukitt medium (Vel, Leuven, Belgium).

Ki-67 antigen staining was carried out using MIB-1 monoclonal antibody (Dako) and the anti-mouse detection method described previously. 


\section{Computer-assisted quantification of immunostaining}

Quantification of immunostaining was performed following the same methodology as previously published [7]. Galectin and $\mathrm{Ki}-67$ stainings were studied in 10 randomly selected areas of well-preserved bronchial epithelium, defined by the presence of basal and columnar cells without detachment from the basement membrane, on each section (three to 11 per subject), in both large and small airways. Leukocyte infiltration was evaluated in 10 randomly selected areas of epithelium, 10 areas of lamina propria and 10 areas of submucosal glands on each section. Large airways were defined as cartilaginous bronchi with submucosal glands and small airways as membranous bronchioles, without cartilage or glands and with an internal diameter $<2 \mathrm{~mm}$, as previously described elsewhere [21]. Two to nine different airways per slide and a total of 10 to 21 large airways and nine to 28 small airways per subject were evaluated. A total of 30, 34 and 45 tissue sections were analysed in the nonsmokers, smokers and COPD groups, respectively.

Computer-assisted quantification of the staining in the selected areas was carried out using a SAMBA 2005 system (Alcatel TITN, Grenoble, France) equipped with a colour camera and an optical microscope (Olympus BX 50; Olympus Optica Company Ltd, Tokyo, Japan), using a final magnification of $400 \times$. Results were expressed as the mean optical density (measured in arbitrary units), representing the mean intensity of staining in the considered area, and as the labelling index (measured as per cent), representing the percentage of surface staining with respect to the total area selected, therefore, reflecting relative numbers of positive cells.

\section{Statistical methods}

The staining indices in the different sections from each patient were subjected to statistical analysis. Two types of comparisons were performed. First, a mean value was calculated for each patient from the staining indices obtained in the different sections and comparisons between groups (COPD versus controls) were performed using the Mann-Whitney U-test. Secondly, within-group comparisons were performed on paired data (large versus small airways) obtained in the same section (where both large and small airways were present) using the Wilcoxon matched-pairs test. Correlations were tested using the nonparametric Kendall test or Spearman's method as appropriate. A p-value $<0.05$ was considered statistically significant. Results were expressed as medians and ranges.

\section{RESULTS}

Airway expression of galectin-1 and -3 in COPD and control patients

Galectin-1 expression was detected in the bronchial epithelium from control and COPD patients (fig. 1a), as well as in the lamina propria notably in endothelial cells (data not shown). Galectin-3 immunostaining was observed in bronchial epithelial cells, especially in the cytoplasm of ciliated and seroglandular cells (fig. 1b), whereas staining was also observed in macrophages (fig. 1b).

While no change in galectin expression was observed in the large airways, the bronchial epithelium of smokers exhibited increased galectin-1 expression in the small airways, as
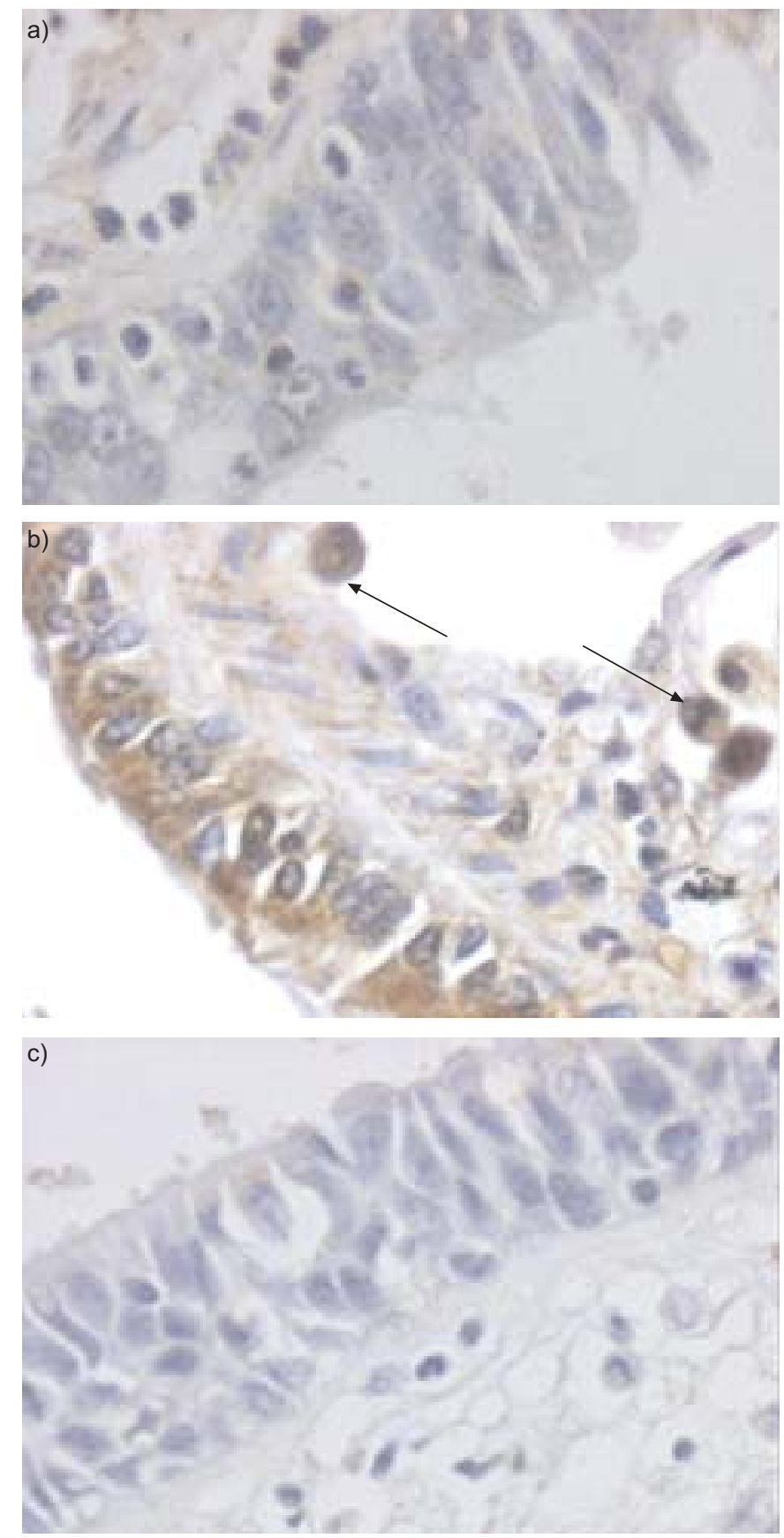

FIGURE 1. a) Galectin-1 and b) galectin-3 staining in the small airways from a chronic obstructive pulmonary disease patient and c) control staining with normal rabbit serum. Arrows represent galectin-3 expression observed in alveolar macrophages.

compared with nonsmokers (approximate three-fold increase; $\mathrm{p}<0.001$; fig. 2). In COPD, galectin-1 expression also tended to increase $(p=0.06$, as compared with nonsmokers), but to a much lower extent than in smokers (fig. 2).

In contrast, expression of galectin-3 in the small airway epithelium, which tended to increase in smokers $(p=0.06)$, was strongly increased in COPD (approximate two-fold increase; $\mathrm{p}<0.001$; fig. 2). 

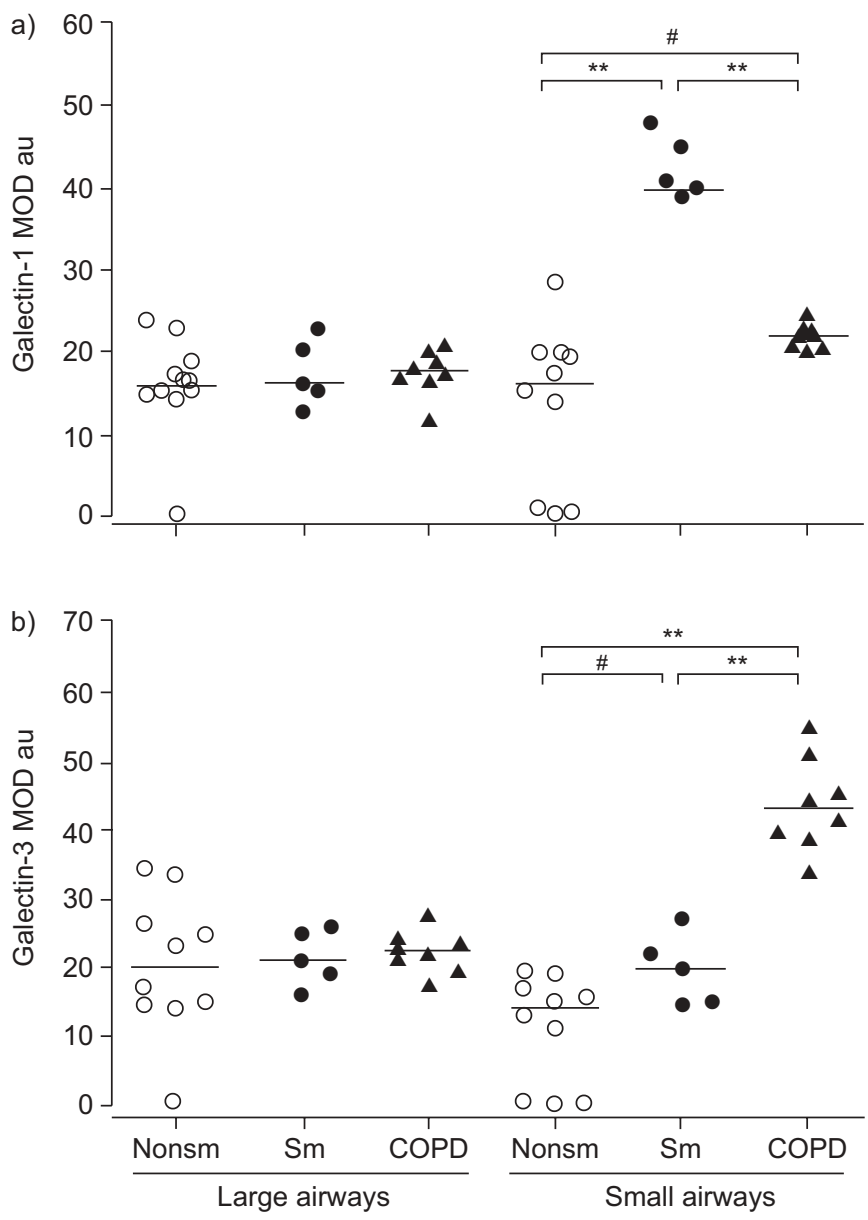

FIGURE 2. Staining indices of galectin- 1 and -3 expression in the bronchial epithelium. Epithelial expression of a) galectin-1 and b) galectin-3 in large and small airways from chronic obstructive pulmonary disease (COPD) patients versus nonsmokers (Nonsm) and smokers ( $\mathrm{Sm}$ ) is shown in terms of mean optical density (MOD). The horizontal bars represent the medians. au: arbitrary units. $* *: p<0.01$; \#: $p=0.06$ (Mann-Whitney U-test).

\section{Ki-67 expressing epithelial cells in COPD and control airways}

Numbers of Ki-67 expressing epithelial cells were significantly increased in small airways of patients with severe COPD, as compared with smokers ( $\mathrm{p}=0.05$; fig. 3 ). No significant changes in Ki-67 staining were observed in COPD large airways (data not shown).

\section{Neutrophil, macrophage and T-cell infiltration of COPD airways}

Highly significant increases in neutrophil numbers were observed in severe COPD as compared with controls $(\mathrm{p}<0.001$; table 2$)$. When compared with smokers, neutrophils were elevated in submucosal glands and in small, but not large, airways (table 2). Thus, a trend for increased neutrophil numbers was observed within the epithelium of large airways from smokers, as compared with nonsmokers (table 2).

CD68+ monocytes/macrophages were also observed in COPD airways occasionally clustered in foci (data not shown), whereas staining values largely overlapped with those observed in controls (table 2). However, relative numbers of macrophages were significantly increased in small airways of smokers and COPD, as compared with nonsmokers (table 2).

Lymphoid foci were observed around COPD airways (data not shown), with increased T-cell numbers in the epithelium and lamina propria of small airways, as compared with smokers $(p=0.003$ and $p<0.001$, respectively; table 2$)$.

\section{Relationships between galectins, epithelial proliferation,} airway inflammation and lung function

Epithelial galectin-3 expression in small airways did not correlate in COPD with epithelial proliferation or neutrophil infiltration. In the small airways, Ki-67+ cell numbers correlated with neutrophils ( $p=0.03, r=0.76$; fig. 4). Furthermore, intra-epithelial neutrophils correlated with airflow obstruction assessed by the forced expiratory volume in one second (FEV1)/forced vital capacity ratio $(\mathrm{p}=0.001, \mathrm{~K}=-0.93)$ and subepithelial monocyte/ macrophages correlated with FEV1 (fig. 5).

\section{DISCUSSION}

Galectins are secreted lectins that participate in the regulation of neutrophil recruitment and cell apoptosis/proliferation, notably during lung development and inflammatory responses [10-14]. The present study showed for the first time that epithelial expression of galectin-3 is increased in the small airways of severe COPD patients. In contrast, increased galectin-1 in the small airways was observed in smokers without COPD. By assessing large numbers of tissue specimens containing various airway generations (whole explanted lungs and surgical specimens), which probably improved the power to detect between-group differences [22], it was also shown that in severe COPD neutrophils are preferentially micro-localised to the epithelium of the small airways, where they correlate with increased epithelial proliferation and airflow obstruction.

It has been shown that galectin-1 expression is induced in nasal polyps upon corticosteroid therapy and that this may limit

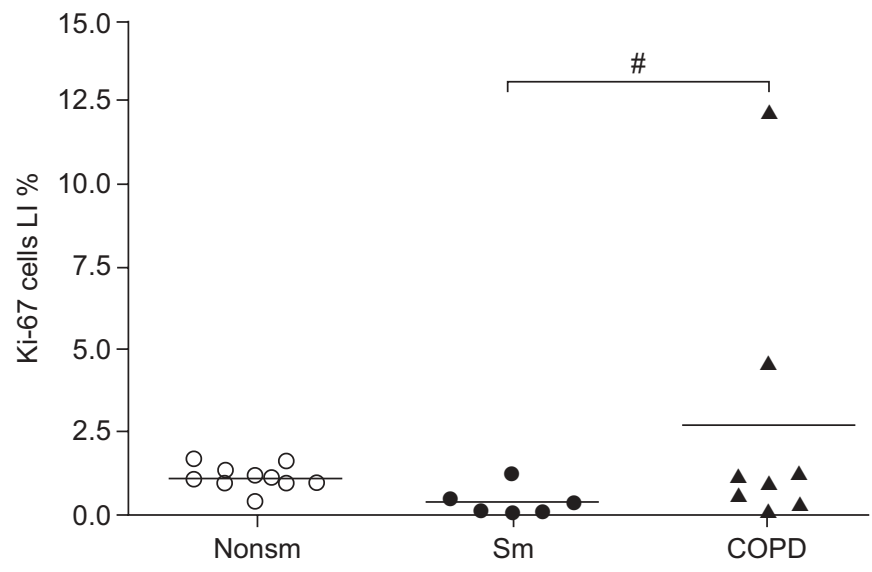

FIGURE 3. Epithelial proliferation (Ki-67 staining) in the bronchial mucosa of chronic obstructive pulmonary disease (COPD) and control patients. Relative numbers (represented by the labelling index (LI)) of Ki-67 expressing epithelial cells are shown in the small airways of patients with severe COPD, nonsmokers (Nonsm) and smokers (Sm). The horizontal bars represent the medians. ${ }^{*}$ : $p=0.05$ (MannWhitney U-test). 


\begin{tabular}{|c|c|c|c|c|c|c|c|c|c|}
\hline & \multicolumn{9}{|c|}{ 니 \% } \\
\hline & \multicolumn{3}{|c|}{ Neutrophils } & \multicolumn{3}{|c|}{ Macrophages } & \multicolumn{3}{|c|}{ T-lymphocytes } \\
\hline & Nonsmokers & Smokers & COPD & Nonsmokers & Smokers & COPD & Nonsmokers & Smokers & COPD \\
\hline \multicolumn{10}{|c|}{ Large airways } \\
\hline Epithelium & $0.03(0-5.7)$ & $0.9(0.2-4.7)$ & $2.9(2.6-4.5)$ & $0.2(0-0.3)$ & $0.8(0.5-1)$ & $0.5(0.4-0.8)$ & $16.7(14.2-23.7)$ & $19.1(15.7-24.5)$ & $18.3(16.1-25.9)$ \\
\hline Lamina & $0.1(0-5.5)$ & $0.1(0-6.8)$ & $2.6(1.9-2.8)$ & $0.4(0.2-0.8)$ & $0.9(0.4-1.5)$ & $0.8(0.7-0.8)$ & $21.5(17.4-23.1)$ & $21.8(18.1-22.7)$ & $22.1(19-23.8)$ \\
\hline Glands & $0.1(0-0.8)$ & $0.4(0.1-1.2)$ & $4.3^{*}(3.8-5.1)$ & $0.3(0.1-0.5)$ & $0.4(0.2-0.6)$ & $0.6(0.5-0.9)$ & $17.9(14.8-25.3)$ & $20(17.4-27.4)$ & $21.9(15-24.8)$ \\
\hline \multicolumn{10}{|c|}{ Small airways } \\
\hline Epithelium & $0.1(0-1.5)$ & $0.1(0-0.8)$ & $5.9^{*}(3.2-6.4)$ & $0.1(0-0.3)$ & $0.8^{\#}(0.5-1.1)$ & $0.9(0.6-1)$ & $32.8(30.1-37.9)$ & $20.8^{\#}(16.9-24.1)$ & $35.2^{*}(22-40.7)$ \\
\hline Lamina & $0.2(0-0.6)$ & $0.2(0.1-0.5)$ & $9.5^{*}(7.2-12.3)$ & $0.2(0.1-0.5)$ & $0.9^{\bullet}(0.7-1.2)$ & $1.8(1.6-1.9)$ & $30.1(30-35.2)$ & $20.1^{\#}(18.2-21.3)$ & $46.1^{*}(35.2-50.8)$ \\
\hline
\end{tabular}

Data are presented as median (range). LI: labelling indices; COPD: chronic obstructive pulmonary disease. *: $p<0.05$, COPD versus smokers; ${ }^{*}$ : $p<0.05$, smokers versus nonsmokers; ${ }^{\bullet}: p=0.06$. All $p$-values were calculated using Mann-Whitney U-tests.

tissue eosinophilia [23]. Decreased galectin-1 and increased galectin-3 expression has been associated with defective apoptosis of synovial mononuclear cells in juvenile idiopathic polyarthritis [24]. A recent study showed that galectin-3 is mitogenic for cardiac fibroblasts, induces collagen deposition and may lead to ventricular dysfunction [25]. In the lung, epithelial expression of galectin-3 is increased in nonsmall lung cancer [26, 27], while in murine asthma models, gene therapy targeted to galectin-3 inhibits allergen-induced airway inflammation, including IL-5 expression, and epithelial mucous metaplasia [28-30]. Secretion of galectin-3 is also upregulated in a rat model of radiation-induced lung fibrosis [31, 32].

Changes in galectin expression observed in the present study could be relevant to COPD pathogenesis, as galectins control apoptosis of epithelial and inflammatory cells as well as neutrophil and macrophage activation. Thus, galectin-3 participates in the recruitment of neutrophils and triggers their release of oxygen radicals and elastase [14], which are thought to mediate the lung destruction induced by cigarette smoking [33]. However, the present study focused on the airways and not on the lung parenchyma, where an increased apoptotic rate of alveolar epithelial and endothelial cells could underlie the development of emphysema [34], including in end-stage COPD $[35,36]$. The altered galectin balance between galectin- 1 and -3 in the small airways could favour the hyperplasia of the bronchial epithelium observed in COPD. Increased numbers of proliferating (expressing Ki-67) epithelial cells were observed in COPD small airways, as previously reported in squamous metaplastic areas of large bronchi [37]. Elevated Ki-67 expression was also previously observed in the lung alveolar wall from severe COPD patients [38], whereas it remained unchanged from controls in another study [36]. Interestingly, in the present study Ki-67+ epithelial cell numbers in small airways correlated with neutrophils, suggesting a link between inflammation and tissue remodelling. Accordingly, increased $\mathrm{Ki}-67+$ epithelial cells following allergen challenge were related in asthma to airway eosinophilia [39]. Alternatively, these correlations could be due to the presence of intra-epithelial inflammatory cells expressing Ki-67 antigen. Although this possibility cannot be excluded, Ki-67 staining could not be related to epithelial infiltration by neutrophils via examination of serial sections of COPD stained for Ki-67 and neutrophils (data not shown).

Smokers without COPD display increased galectin-1 expression in the bronchial epithelium of small airways in parallel to a trend for increase in galectin-3, suggesting that the impaired balance between galectin- 1 and -3 favouring airway inflammation and remodelling is only observed in susceptible smokers who develop COPD. It is tempting to speculate that in nonsusceptible smokers galectin-1 could help to suppress signals of inflammatory and proliferative responses. However, the present study was not designed to address the mechanisms of these changes, which could relate to intrinsic changes of the COPD bronchial epithelium or to nonspecific factors associated with severe disease, such as hypoxia [40]. Also a putative effect of the treatment of COPD cannot be ruled out, although it seems unlikely that inhaled corticosteroid treatment could account for the observed changes in galectin expression [23].

The present study did not document a correlation between epithelial galectin-3 expression and neutrophil accumulation in severe COPD patients. As previously demonstrated [41-45], neutrophil infiltration of the airways of severe COPD patients was observed. The present authors showed that neutrophils in severe COPD patients are more particularly localised in submucosal glands and the small airways, a latter feature in contrast with mild stage COPD [46-48]. Smokers were characterised by neutrophil infiltration of proximal bronchi, particularly within the epithelium. As previously reported elsewhere [43, 45], macrophage numbers largely overlapped those observed in smokers, although in the present study a trend for increase was observed in the small airways.

Regarding T-cells, a nonsignificant difference between groups was observed in the large airways. This is in contrast with previous studies of mild-to-moderate COPD showing increased subepithelial CD3 [42, 44, 45] and CD8 cells [44, 45] in large airways. Conversely, in a study in severe COPD by DI STEFANO et al. [49], CD3 and CD8 cell numbers were decreased and inversely correlated with the degree of airflow limitation, suggesting that cigarette smoke-induced 


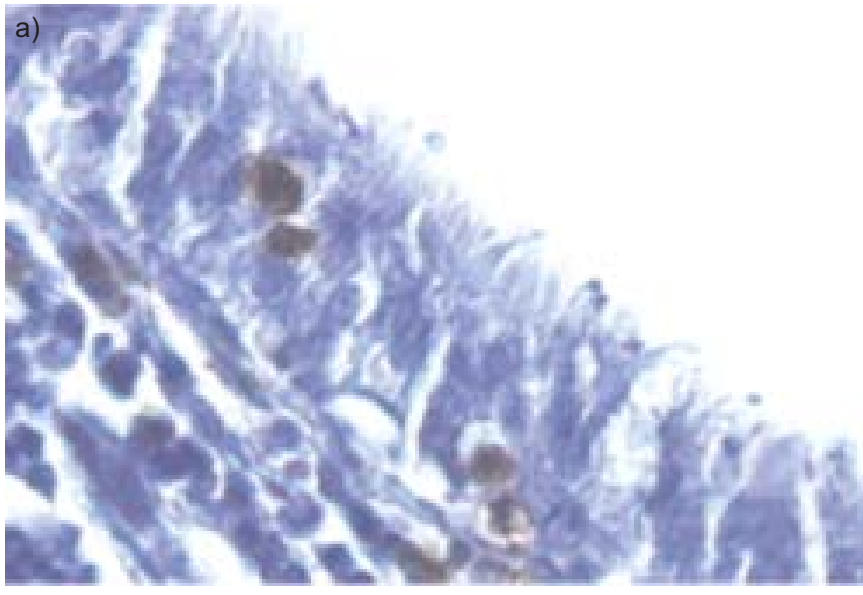

c)

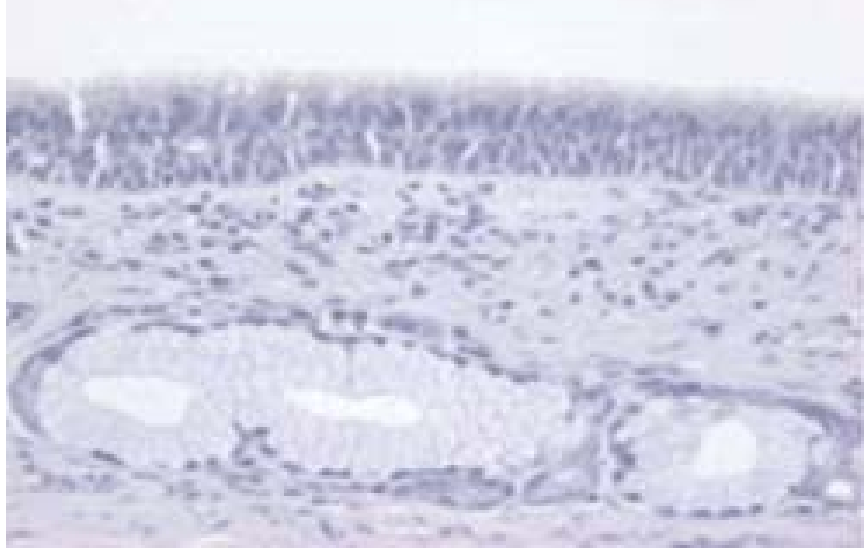

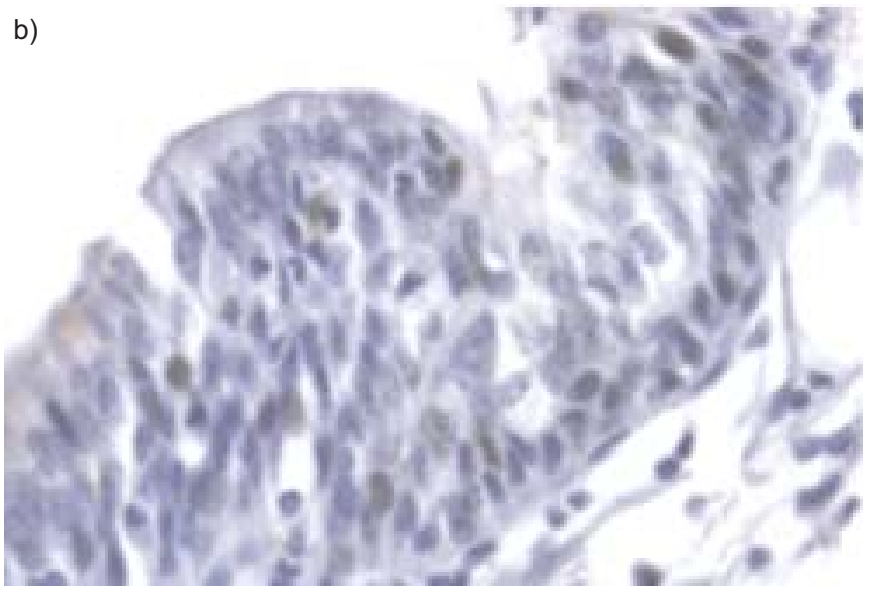

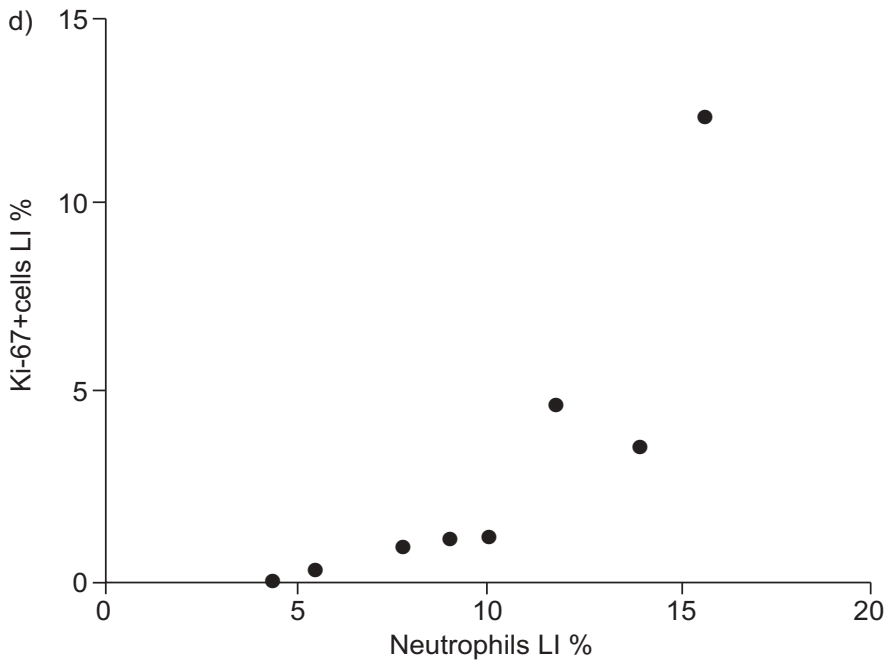

FIGURE 4. Relationship between a) neutrophils (brown-stained cells) and b) Ki-67+ epithelial cells (brown-stained cells) in small airways of severe chronic obstructive pulmonary disease (COPD) patients. c) A representative isotypic (mouse immunoglobulin G1 k) control. d) Neutrophils were plotted against Ki-67+ proliferating epithelial cells in the small airways of severe COPD patients according to the Spearman's method. LI: labelling index. $p=0.03, r=0.76$.
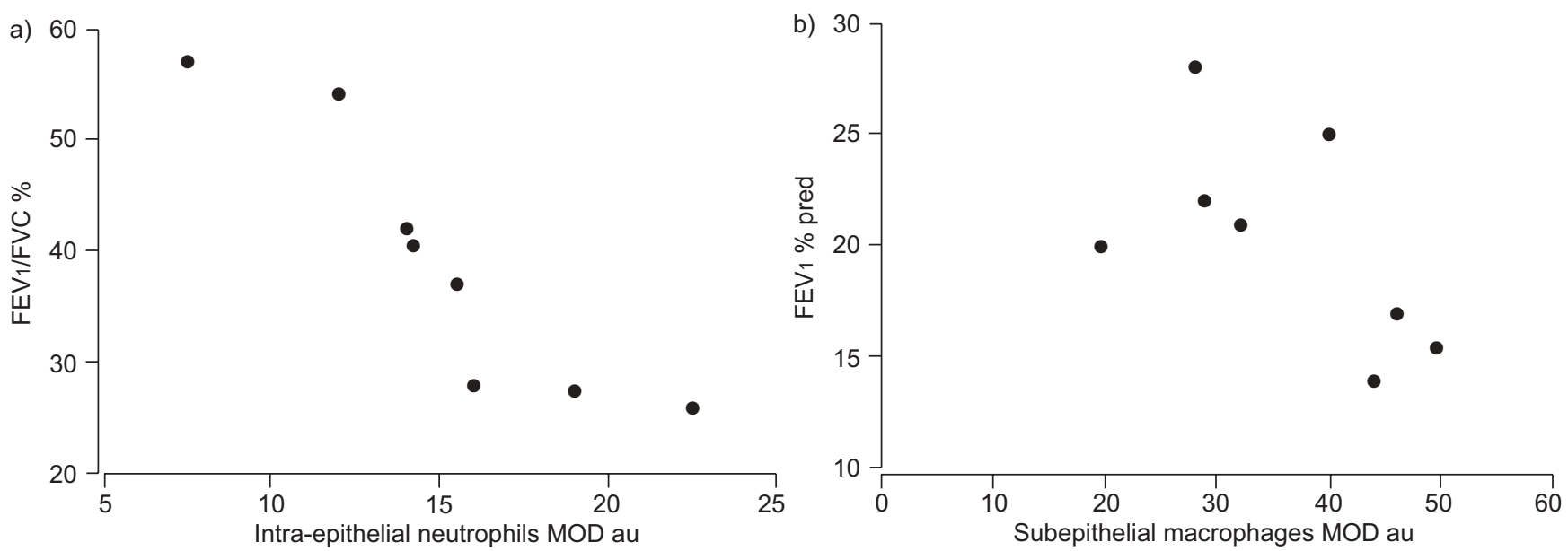

FIGURE 5. Relationship between neutrophils, macrophages and lung function in the small airways of severe chronic obstructive pulmonary disease patients. Functional parameters of airway obstruction (forced expiratory volume in one second (FEV1) and FEV1/forced vital capacity (FVC) ratio) plotted against a) intra-epithelial neutrophils $(p=0.001, k=-0.93)$ and $b)$ subepithelial macrophages $(p=0.03, k=-0.73)$ expressed as mean optical density (MOD) values. \% pred: \% predicted; au: arbitrary units. $K$ (Kendall's tau) and p-values were calculated according to the Kendall test. 
bronchial inflammation is downregulated as the disease progresses. Alternatively, severe COPD could represent a particular subgroup of COPD patients with a distinct immunological phenotype. However, the present findings confirm that T-cells infiltrate the small airways of severe COPD patients, as observed in COPD lung parenchyma [50] and around lung vessels [51], a fact that is in agreement with a previous study in severe COPD [52] and that had been reported previously in mild COPD cases [48]. Furthermore, it is shown that a decrease in T-cell numbers characterises smokers without COPD as compared with nonsmokers. As previously suggested [45], this observation could relate to the selection of a subpopulation of smoking subjects with low CD3 cell counts who are more resistant to the effect of cigarette smoke.

Micro-localisation of neutrophils to smooth muscle has recently been reported in COPD [53] and related to local expression of CXC chemokines [54]. Similarly, localisation of mast cells within peribronchial smooth muscle in asthma [55] has been associated with the release of CXCL10 by smooth muscle cells [56]. This study shows that intra-epithelial, in contrast to subepithelial, micro-localisation of neutrophils in severe COPD correlates with airway obstruction. In addition to the production of galectin-3 reported in the present study, bronchial epithelial cells can express CXC chemokines and adhesion molecules that may facilitate the trafficking of neutrophils to the airway epithelium. Conversely, neutrophilderived products, such as elastase, can contribute in COPD to locally activated epithelial cells and trigger transcriptional programmes leading to epithelial expression of pro-inflammatory mediators. The present authors observed that subepithelial macrophages also correlate with airflow limitation, suggesting that in COPD inflammatory cells have different functional implications within the various airway microcompartments [57].

Although the small numbers of patients limit the conclusions, the present study provided further evidence of important changes occurring in the bronchial epithelium of patients with severe COPD. Upregulated galectin-3 expression, unbalanced by galectin- 1 , is observed in the small airways of smokers who have developed severe COPD, in contrast with smokers without COPD who tend to display the opposite expression profile. Although other factors appear involved, changes in galectin expression could contribute to epithelial hyperplasia and neutrophil accumulation in the airways of COPD patients. It is noteworthy that the emerging involvement of galectin-2 in T-cell regulation and the pathogenesis of myocardial infarction highlights the importance of further analysis of the galectin network in lung diseases [58-60].

The present study showed for the first time that in severe chronic obstructive pulmonary disease the small airway epithelium is a particular site of neutrophil infiltration, related to epithelial proliferation and airflow limitation. The findings support previous studies [61], which proposed an important role for small conducting airways in the pathophysiology of chronic obstructive pulmonary disease. It is suggested that chronic damage to the epithelium is associated in susceptible smokers with increased galectin- 3 expression and that microlocalisation of neutrophils to the small airway epithelium is a particular and functionally relevant feature in severe chronic obstructive pulmonary disease.

\section{ACKNOWLEDGEMENTS}

The authors would like to thank P. Thurion (Laboratory of Histopathology, University of Louvain, Mont-Godinne, Belgium) for his excellent technical assistance and I. Salmon, C. Decaestecker and N. D'Haene (Laboratory of Histopathology, University of Brussels, Brussels, Belgium) for help with statistical analyses and staining quantification. The authors would also like to thank L. Wilcock (Imperial College London, London, UK) for language revision of the manuscript.

\section{REFERENCES}

1 Pauwels RA, Buist AS, Calverley PM, Jenkins CR, Hurd SS, GOLD Scientific Committee. Global strategy for the diagnosis, management, and prevention of chronic obstructive pulmonary disease. NHLBI/WHO Global Initiative for Chronic Obstructive Lung Disease (GOLD) Workshop summary. Am J Respir Crit Care Med 2001; 163: 1256-1276.

2 Di Stefano A, Maestrelli P, Roggeri A, et al. Upregulation of adhesion molecules in the bronchial mucosa of subjects with chronic obstructive bronchitis. Am J Respir Crit Care Med 1994; 149: 803-810.

3 Saetta M, Mariani M, Panina-Bordignon P, et al. Increased expression of the chemokine receptor CXCR3 and its ligand CXCL10 in peripheral airways of smokers with chronic obstructive pulmonary disease. Am J Respir Crit Care Med 2002; 165: 1404-1409.

4 Jeffery PK. Lymphocytes, chronic bronchitis and chronic obstructive pulmonary disease. Novartis Found Symp 2001; 234: 149-161.

5 Jeffery PK. Remodeling in asthma and chronic obstructive lung disease. Am J Respir Crit Care Med 2001; 164: S28-S38.

6 De Boer WI. Cytokines and therapy in COPD: a promising combination? Chest 2002; 121: Suppl. 5, S209-S218.

7 Pilette C, Godding V, Kiss R, et al. Reduced epithelial expression of secretory component in small airways correlates with airflow obstruction in chronic obstructive pulmonary disease. Am J Respir Crit Care Med 2001; 163: 185-194.

8 Pilette C, Ouadrhiri Y, Dimanche F, Vaerman JP, Sibille Y. Secretory component is cleaved by neutrophil serine proteinases but its epithelial production is increased by neutrophils through NF-кB- and p38 mitogen-activated protein kinase-dependent mechanisms. Am J Respir Cell Mol Biol 2003; 28: 485-498.

9 Gabius H-J, Siebert HC, André S, Jiménez-Barbero J, Rüdiger $H$. Chemical biology of the sugar code. Chembiochem 2004; 5: 740-764.

10 Gabius H-J. Cell surface glycans: the why and how of their functionality as biochemical signals in lectin-mediated information transfer. Crit Rev Immunol 2006; 26: 43-79.

11 Powell JT, Harrison JL. The sugared path to a normal lung: soluble $\beta$-galactoside-specific lectins. Am J Physiol Lung Cell Mol Physiol 1991; 261: L236-L239.

12 Kaltner H, Seyrek K, Heck A, Sinowatz F, Gabius HJ. Galectin-1 and galectin-3 in fetal development of bovine 
respiratory and digestive tracts. Comparison of cell typespecific expression profiles and subcellular localization. Cell Tissue Res 2002; 307: 35-46.

13 Hughes RC. Mac-2: a versatile galactose-binding protein of mammalian tissues. Glycobiology 1994; 4: 5-12.

14 Rabinovich GA, Rubinstein N, Toscano MA. Role of galectins in inflammatory and immunomodulatory processes. Biochim Biophys Acta 2002; 1572: 274-284.

15 van den Brule FA, Buicu C, Berchuck A, et al. Expression of the $67-\mathrm{kD}$ laminin receptor, galectin-1, and galectin-3 in advanced human uterine adenocarcinoma. Hum Pathol 1996; 27: 1185-1191.

16 Liu FT, Patterson RJ, Wang JL. Intracellular functions of galectins. Biochim Biophys Acta 2002; 1572: 263-273.

17 Sato S, Ouellet N, Pelletier I, Simar M, Rancourt A, Bergeron MG. Role of galectin-3 as an adhesion molecule for neutrophil extravasation during streptococcal pneumonia. J Immunol 2002; 168: 1813-1822.

18 Wang J, Barke RA, Charboneau R, Roy S. Morphine impairs host innate immune response and increases susceptibility to Streptococcus pneumoniae lung infection. J Immunol 2005; 174: 426-434.

19 André S, Kojima S, Yamazaki N, et al. Galectins-1 and -3 and their ligands in tumor biology. Non-uniform properties in cell-surface presentation and modulation of adhesion to matrix glycoproteins for various tumor cell lines, in biodistribution of free and liposome-bound galectins and in their expression by breast and colorectal carcinomas with/without metastatic propensity. J Cancer Res Clin Oncol 1999; 125: 461-474.

20 Nagy N, Legendre H, Engels O, et al. Refined prognostic evaluation in colon carcinoma using immunohistochemical galectin fingerprinting. Cancer 2003; 97: 1849-1858.

21 Mullen JB, Wright JL, Wiggs BR, Pare PD, Hogg JC. Structure of central airways in current smokers and exsmokers with and without mucus hypersecretion: relationship to lung function. Thorax 1987; 42: 843-848.

22 Gamble E, Qiu Y, Wang D, et al. Variability of bronchial inflammation in chronic obstructive pulmonary disease: implications for study design. Eur Respir J 2006; 27: 293-299.

23 Delbrouck C, Doyen I, Belot N, et al. Galectin-1 is overexpressed in nasal polyps under budesonide and inhibits eosinophil migration. Lab Invest 2002; 82: 147-158.

24 Harjacek M, Díaz-Cano S, De Miguel M, Wolfe H, Maldonado CA, Rabinovich GA. Expression of galectins1 and -3 correlates with defective mononuclear cell apoptosis in patients with juvenile idiopathic arthritis. J Rheumatol 2001; 28: 1914-1922.

25 Sharma UC, Pokharel S, van Brakel TJ, et al. Galectin-3 marks activated macrophages in failure-prone hypertrophied hearts and contributes to cardiac dysfunction. Circulation 2004; 110: 3121-3128.

26 Yoshimura A, Gemma A, Hosoya Y, et al. Increased expression of the LGALS3 (galectin 3) gene in human non-small-cell lung cancer. Genes Chromosomes Cancer 2003; 37: 159-164.

27 Mathieu A, Saal I, Vuckovic A, et al. Nuclear galectin-3 expression is an independent predictive factor of recurrence for adenocarcinoma and squamous cell carcinoma of the lung. Mod Pathol 2005; 18: 1264-1271.
28 del Pozo V, Rojo M, Rubio ML, et al. Gene therapy with galectin-3 inhibits bronchial obstruction and inflammation in antigen-challenged rats through interleukin-5 gene downregulation. Am J Respir Crit Care Med 2002; 166: 732-737.

29 Zuberi RI, Hsu DK, Kalayci O, et al. Critical role for galectin-3 in airway inflammation and bronchial hyperresponsiveness in a murine model of asthma. Am J Pathol 2004; 165: 2045-2053.

30 López E, del Pozo V, Miguel T, et al. Inhibition of chronic airway inflammation and remodeling by galectin-3 gene therapy in a murine model. J Immunol 2006; 176: 1943-1950.

31 Kasper M, Hughes RC. Immunocytochemical evidence for a modulation of galectin 3 (Mac-2), a carbohydrate binding protein, in pulmonary fibrosis. J Pathol 1996; 179: 309-316.

32 Kasper M, Fehrenbach H. Immunohistochemical evidence for the occurrence of similar epithelial phenotypes during lung development and radiation-induced fibrogenesis. Int J Radiat Biol 2000; 76: 493-501.

33 Senior RM, Tegner H, Kuhn C, Ohlsson K, Starcher BC, Pierce JA. The induction of pulmonary emphysema with human leukocyte elastase. Am Rev Respir Dis 1977; 116: 469-475.

34 Kasahara Y, Tuder RM, Cool CD, Lynch DA, Flores SC, Voelkel NF. Endothelial cell death and decreased expression of vascular endothelial growth factor and vascular endothelial growth factor receptor 2 in emphysema. Am J Respir Crit Care Med 2001; 163: 737-744.

35 Imai K, Mercer BA, Schulman LL, Sonett JR, D'Armiento JM. Correlation of lung surface area to apoptosis and proliferation in human emphysema. Eur Respir J 2005; 25: 250-258.

36 Calabrese F, Giacometti C, Beghe B, et al. Marked alveolar apoptosis/proliferation imbalance in end-stage emphysema. Respir Res 2005; 6: 14.

37 Aarbiou J, van Schadewijk A, Stolk J, et al. Human neutrophil defensins and secretory leukocyte proteinase inhibitor in squamous metaplastic epithelium of bronchial airways. Inflamm Res 2004; 53: 230-238.

38 Yokohori N, Aoshiba K, Nagai A, Respiratory Failure Research Group in Japan. Increased levels of cell death and proliferation in alveolar wall cells in patients with pulmonary emphysema. Chest 2004; 125: 626-632.

39 Ricciardolo FL, Di Stefano A, van Krieken JH, et al. Proliferation and inflammation in bronchial epithelium after allergen in atopic asthmatics. Clin Exp Allergy 2003; 33: 905-911.

40 Greijer AE, van der Groep P, Kemming D, et al. Upregulation of gene expression by hypoxia is mediated predominantly by hypoxia-inducible factor 1 (HIF-1). J Pathol 2005; 206: 291-304.

41 Di Stefano A, Capelli A, Lusuardi M, et al. Severity of airflow limitation is associated with severity of airway inflammation in smokers. Am J Respir Crit Care Med 1998; 158: 1277-1285.

42 Saetta M, Di Stefano A, Maestrelli P, et al. Activated Tlymphocytes and macrophages in bronchial mucosa of subjects with chronic bronchitis. Am Rev Respir Dis 1993; 147: 301-306.

43 Di Stefano A, Turato G, Maestrelli P, et al. Airflow limitation in chronic bronchitis is associated with T- 
lymphocyte and macrophage infiltration of the bronchial mucosa. Am J Respir Crit Care Med 1996; 153: 629-632.

44 O'Shaughnessy TC, Ansari TW, Barnes NC, Jeffery PK. Inflammation in bronchial biopsies of subjects with chronic bronchitis: inverse relationship of CD8+ $\mathrm{T}$ lymphocytes with FEV1. Am J Respir Crit Care Med 1997; 155: 852-857.

45 Lams BE, Sousa AR, Rees PJ, Lee TH. Subepithelial immunopathology of the large airways in smokers with and without chronic obstructive pulmonary disease. Eur Respir J 2000; 15: 512-516.

46 Grashoff WF, Sont JK, Sterk PJ, et al. Chronic obstructive pulmonary disease: role of bronchiolar mast cells and macrophages. Am J Pathol 1997; 151: 1785-1790.

47 Saetta M, Di Stefano A, Turato G, et al. CD8+ Tlymphocytes in peripheral airways of smokers with chronic obstructive pulmonary disease. Am J Respir Crit Care Med 1998; 157: 822-826.

48 Saetta M, Turato G, Baraldo S, et al. Goblet cell hyperplasia and epithelial inflammation in peripheral airways of smokers with both symptoms of chronic bronchitis and chronic airflow limitation. Am J Respir Crit Care Med 2000; 161: 1016-1021.

49 Di Stefano A, Capelli A, Lusuardi M, et al. Decreased T lymphocyte infiltration in bronchial biopsies of subjects with severe chronic obstructive pulmonary disease. Clin Exp Allergy 2001; 31: 893-902.

50 Saetta M, Baraldo S, Corbino L, et al. CD8+ve cells in the lungs of smokers with chronic obstructive pulmonary disease. Am J Respir Crit Care Med 1999; 160: 711-717.

51 Peinado VI, Barbera JA, Abate P, et al. Inflammatory reaction in pulmonary muscular arteries of patients with mild chronic obstructive pulmonary disease. Am J Respir Crit Care Med 1999; 159: 1605-1611.

52 Turato G, Zuin R, Miniati M, et al. Airway inflammation in severe chronic obstructive pulmonary disease: relationship with lung function and radiologic emphysema. Am J Respir Crit Care Med 2002; 166: 105-110.

53 Baraldo S, Turato G, Badin C, et al. Neutrophilic infiltration within the airway smooth muscle in patients with COPD. Thorax 2004; 59: 308-312.

54 Saetta M, Baraldo S, Zuin R. Neutrophil chemokines in severe exacerbations of chronic obstructive pulmonary disease: fatal chemo-attraction? Am J Respir Crit Care Med 2003; 168: 911-913.

55 Brightling CE, Bradding P, Symon FA, Holgate ST, Wardlaw AJ, Pavord ID. Mast-cell infiltration of airway smooth muscle in asthma. N Engl J Med 2002; 346: 1699-1705.

56 Brightling CE, Ammit AJ, Kaur D, et al. The CXCL10/ CXCR3 axis mediates human lung mast cell migration to asthmatic airway smooth muscle. Am J Respir Crit Care Med 2005; 171: 1103-1108.

57 Battaglia S, Mauad T, van Schadewijk AM, et al. Differential distribution of inflammatory cells in large and small airways in smokers. J Clin Pathol 2006; [Epub ahead of print, PMID: 16917001].

58 Ozaki K, Inoue $\mathrm{K}$, Sato $\mathrm{H}$, et al. Functional variation in LGALS2 confers risk of myocardial infarction and regulates lymphotoxin- $\alpha$ secretion in vitro. Nature 2004; 429: 72-75.

59 Sturm A, Lensch M, André S, et al. Human galectin-2: novel inducer of $\mathrm{T}$ cell apoptosis with distinct profile of caspase activation. J Immunol 2004; 173: 3825-3837.

60 Villalobo A, Nogales-González A, Gabius HJ. A guide to signaling pathways connecting protein-glycan interaction with the emerging versatile effector functionality of mammalian lectins. Trends Glycosci Glycotechnol 2006; 18: 1-37.

61 Cosio M, Ghezzo H, Hogg JC, et al. The relations between structural changes in small airways and pulmonaryfunction tests. N Engl J Med 1978; 298: 1277-1281. 